Daria S. Nielsen (iD https://orcid.org/0000-0003-2616-2289

Uniwersytet Łódzki / Uniwersytet w Sztokholmie

e-mail: daria.nielsen@uni.lodz.pl

Kim Skjoldager-Nielsen (iD https://orcid.org/0000-0002-2577-9538

Uniwersytet Łódzki / Uniwersytet w Sztokholmie

e-mail: kim.skjoldager-nielsen@teater.su.se

Otrzymano/Received: 24.04.2020

Zaakceptowano/Accepted: 4.05.2020

Opublikowano/Published: 18.05 .2020

\title{
The (Ir)replaceable Master Director - Considering the Case of the Odin Teatret
}

Abstract

In 2019, a call for a new director for Nordisk Teaterlaboratorium - Odin Teatret was published. This, however, did not mean that the artistic leader of the group theatre Odin Teatret, Eugenio Barba, was to be replaced completely - there is a distinction between the laboratory and the theatre. In this article, we explore the problem of the passing on legacy and tradition from one generation to another in group theatres such as Odin Teatret. We ask: (1) How would it have been possible to continue after such a visionary director retired? (2) Would the next step be continuation or something new? In search for the answers we discuss the history, method, and dramaturgy of Odin Teatret and Barba, as well as the process of generational change in the laboratory, using documents which assess the situation of the organization and analyzing Barba's theoretical writings. We consider them in terms of transformational leadership theory. In conclusion, we deliberate on possible scenarios of the generational change in group theatres that could provide a balance between keeping the tradition and implementing the new vision.

Keywords: Eugenio Barba, Odin Teatret, transformational leadership, generational change, change of director

Słowa kluczowe: Eugenio Barba, Odin Teatret, przywództwo transformacyjne, zmiana pokoleniowa, zmiana dyrektora 
The knowledge acquired on my island is the only one I can talk about with the certainty of things experienced, suffered, enjoyed and partially understood by me. It is a knowledge closely linked to my biography and that of my companions. But even those who continue to accept me as their director, would not know how to put into practice my way of directing. Every head is a different jungle. It is more than enough if each of us succeeds in opening clearings and paths in our own particular one. Therefore, I cannot, nor do wish to, pass on a style, create a school or a method, or - to use a word that I don't like - define a personal aesthetic that others might share [Barba, 2010: xv].

In 2019, a new director was to be found for Nordisk Teaterlaboratorium - Odin Teatret. This, however, did not mean that the artistic leader of the group theatre Odin Teatret, Eugenio Barba, was to be replaced completely. There is a distinction between the laboratory and the theatre group; administratively the laboratory is an umbrella organization for different activities including the theatre ensemble. Yet, when we heard this announcement, we wondered if it would at all have been possible to replace the artistic leader as well? In this article, we explore the problem of the passing on legacy and tradition from one generation to another in group theatres such as Odin Teatret, which are run by strong leaders. Despite Barba's explicit and repeated wish not to pass on his method, we ask

1. How would it have been possible to continue after such an influential director retired?

2. Would the next step be continuation or something new?

In search for the answers we examine documents assessing the past and current situation of the organization (especially reports ordered by the state's art council evaluating the performance and plans of the organization and its organizational statutes), webpage resources (especially the call for director that provides insight into the organizational culture and special expectations towards a new employee), and Barba's theoretical and biographical writings, which explain his ideas and views on his leadership style. We consider the history, method, and dramaturgy of Odin Teatret and Barba as reasons both why we think a transition to a new artistic leader would be possible and not possible. Odin Teatret is by many, both inside and outside Denmark, considered a cultural institution in its own right; in fact, one of the most famous group theatres in the world. This gives a reason for preserving its method and tradition, which we are about to lose when the director and members of the group retire, leave or after their demise. We relate this discussion to leadership theory in an attempt to comply with the complexity of the answer.

Even though Barba himself does not have plans for finding a replacement in the ensemble, there is the potentiality of continuation, which might preserve Barba's method. He himself closely connects it with his biography and actors, but this 
method consists of principles which are not unique, as they are practiced by other artists as well (for example, Kirsten Dehlholm of Hotel Pro Forma in Denmark, Wooster Group in USA or Teatr Cricot 2 in Poland). However, it is Odin Teatret's dramaturgy of "the weaving of the performance's elements" that has been established as a new way of understanding and doing dramaturgy within scholarship and dramaturgical practice [Paavolainen 2015: 12; Turner, Behrndt 2008: 12] and as such is being preserved already. Hence, Barba's method can be transferred to somebody else or reused by them as a dramaturgical practice, just like Aristotelian or Brechtian dramaturgy.

\section{Odin Teatret}

After having worked and studied some years in Norway, in 1961 the Italian Eugenio Barba went to Poland to study Theatre Studies at the State Academy of Drama (Państwowa Wyższa Szkoła Teatralna im. Aleksandra Zelwerowicza) in Warsaw. Yet, he only remained there for a year, as he joined Jerzy Grotowski and his Teatr 13 Rzędów in Opole. He was Grotowski's apprentice till 1963 before he went to India to study Kathakali and then back to Norway with the intention of becoming a theatre director. Without recognition from the theatre establishment, Barba formed Odin Teatret in Oslo in 1964 together with a group of young would-be-actors, who had failed to enter the theatre school. The group were struggling as they did not have subvention and proper facilities but managed nonetheless to present their first performance in 1965 and take it on a Nordic tour. In 1966 the Danish municipality of Holstebro in Northwestern Jutland invited Odin Teatret with the intention of developing its local cultural life. Odin Teatret_was given a minimal start-up sum of money and an old farm as base for their rehearsal, training, teaching, seminars and performing - a place where they still remain after 54 years. Since then Odin Teatret has functioned as a group theatre ensemble with Barba as their director. Many of the actors have stayed for years, while some of the founding members are still with the group today. In 1980 it received the status of a regional theatre. To date Odin Teatret has produced 65 performances, which all have toured the world.

\section{Nordisk Teaterelaboratorium - 0din Teatret}

With the move to Holstebro, Odin Teatret established Nordisk Teaterlaboratorium as an umbrella organization to include different activities. First of all, this laboratory initiative was rooted in the idea of training the actors and developing their techniques in ways that were characteristic of Odin Teatret, which soon began to draw the attention of outside actors, directors, and researchers. The laboratory constellation 
made it possible to disseminate the work and acting of the group, house international workshops, seminars, and conferences, which included the ISTA - International School of Theatre Anthropology, setup by Barba in 1989 in collaboration with the University of Bologna.

Currently the laboratory is involved in very large number of very diverse activities. The website lists (besides the activities we mentioned above) many collaborations with other artists, theatre groups, and universities; and organization of local cultural events (as Odin Teatret is very much involved in the local cultural life of Holstebro and the region) [About Odin Teatret], which all follow the purpose from the most recent organizational statute. From the point of view of the upcoming change of the laboratory's director, there is a project that attracts our attention: OTA, i.e. Odin Teatret Archive, ${ }^{1}$ which goal is to preserve a living memory of the theatre. Its mission is to "preserve material about Odin Teatret's history and Nordisk Teaterlaboratorium's activities as well as to support and disseminate pure and applied research in the fields of Theatre Laboratory, acting theories and Third Theatre" [OTA]. This project leaves open door to preserving Barba’s work in different ways. We will deliberate on this topic in the discussion part of this article.

\section{Barba's Method/Dramaturgogy}

Barba's method, which he has extensively written about himself, is based on the individual improvisations by the ensemble actors, who create material, which Barba gradually selects and puts together into what he often refers to as a "performance text" - not to be confused with drama text - but rather a texture or weave of what is to become the performance's material. There might be a conceptual idea for the performance in the beginning, but this might change radically during the work on the performance, which often lasts up till two years. As director Barba is the one, who searches for the life force or bios of the performance as an organic whole. In the choice of material that is to be made, he goes through a process of serendipity with his actors, i.e. discoveries that none of them were expecting to do. Serendipity is known as a process in science that has produced new results, for example, penicillin, and radium. This process, which is open to chance, calls for a certain kind of leadership, which is not set on realizing fixed concepts, but is inspirationally motivating and intellectually stimulating for its participants, in this case the actors.

In the creative process there are three points of view which Barba has named dramaturgies, as they impact and interfere with each other, and make up the final performance. The dramaturgy of the actor is the way the experienced actor develops her material more and more autonomously; the dramaturgy of the director is the way

\footnotetext{
1 Sometimes referred to as a Living Archive or Odin Teatret Living Archive.
} 
the director works with and shapes the actor's dramaturgy in order to set in motion the spectator's dramaturgy. Barba admits that the last one is the most difficult to work with as a dramaturgy, but in doing so he has strived for a performance experience that could give the spectators both a sense of communality and individuality.

He understands the performance material as three levels in dramaturgical terms: (1) the organic, which has to do with the composition and interweaving of the energetics of the physical and vocal action of the actors that affect the spectator's senses; (2) the narrative, which are actions that convey to the spectator the meaning of the performance, and (3) the evocative, which brings forth the unintentional or unexpected meaning to the individual spectator. Even though the creative process is very much a collective one, when considering the immense contribution by the actors, Barba is still the person who inspires that process, finally makes the choices of material and puts it together in a montage.

\section{Transformational leadership}

The group theatres, as we know them from the 1960s and onward, are frequently congregated around one leader, who often stays in charge of the group for decades just like in the case of Odin Teatret and Eugenio Barba. The leader of a group theatre can be described as a person that gathers followers who wish to create under their artistic vision and adopt their working method. The leader's vision and charisma, which allow them to keep their followers, seem to influence the development and existence of group theatres, but it can also be a consideration for the possibility for changing the leader and theatre's future.

Even though recent models of leadership emphasize the idea of "distributed leadership" [see Bolden 2011], the earlier leadership approaches - which look at leadership as reciprocal activity, but still emphasize the importance of one leader - seem more applicable for the case of group theatres (as well as other cultural organizations ${ }^{2}$ ). We propose to discuss transformational leadership [Burns 1978] in the context of leaders of group theatres, as it transcends or transforms the values of the followers, empowers them, and inspires better performance.

Developing Burns' model, Bass and Avolio [1994] identified the 4Is characteristic to transformational leadership:

A. Idealized influence (charisma) - the leader is influential about ideals and serves as a role model for the followers;

2 For research concerning orchestras with focus on influence of conductor's leadership style and musicians' group mood/emotions on the artistic quality of the orchestra, see Boerner, von Streit [2005 and 2007]; Rowold, Rohmann [2009]. 
B. Inspirational motivation - the leader inspires and motivates the followers;

C. Intellectual stimulation - the leader supports followers' creativity;

D. Individualized consideration - the leader gives personal attention to the followers and supports their development.

This means that transformational leaders are charismatic and inspiring (or, in other words, able to pass on their vision) to their followers; they encourage intellectual growth of the individuals by motivating them to look at issues and ideas in a new way. Those features of the leader are particularly evident in Barba's style of work: he lets the actors create material through improvisation, he encourages their creativity and inspires their work [see Barba 2010: 76-77]. This approach to work exemplifies how Bratton describes transformational leadership: "the power of the human synergy between leaders and followers" [Bratton ed. 2020: 158]. With the devoted team leader the group can reach better results.

Transformational leadership brings out specific features of the leader's followers - Bass observes that " $[\mathrm{m}]$ embers of transformational teams care about each other, intellectually stimulate each other, inspire each other, and identify with the team's goals" [Bass 1999: 11]. As research shows, those outcomes are possible due to two parallel results that transformational leadership produces: empowerment and dependency of the followers [Kark, Shamir, Chen 2003]. Even though those results may seem as opposite outcomes (empowerment belonging to a "good" leadership and dependency to the "bad" one), Kark et al. proved that those results are not opposite, but come from two different sources:

followers' dependence is mediated by followers' personal identification with the leader whereas the relationship between transformational behaviors and followers' empowerment is mediated by followers' identification with the work group [Kark et al. 2003: 246].

Personal identification refers to how each individual forms their relationship with a leader: they shape beliefs, values, feelings, and behaviors accordingly, treat the leader as a role model. Social identification refers to identifying with a group (or organization), building their self-esteem on this belonging, treating successes and failures of the group personally. This demonstrates that transformational leadership may produce a creative and stimulating environment, which is crucial for the long-term development of the artistic group. This goes especially for Odin Teatret, since it has formed a community of actors that were not trained by the established theatre. In the theatre laboratory they created their own training programs. Some of them work with Odin Teatret since the 1960s, when it was established. Reports show [Bak 2014; Adrian 2019] that social identification is strong among the members of the ensemble and laboratory. The call for a new director, which will be discussed in the next part of the article, communicates emotional relationship towards the organization. Reading of Barba's work [2010] allows us to assume that personal 
identification of the group members with the leader is also strong in Odin Teatret. However, the affirmation of this assumption requires further study.

Nevertheless, its positive results, transformational leadership may also lead to undesirable outcomes [see Northouse 2012: 202-204; Bolden et al. 2011: 155-156; Bratton ed. 2020: 165-166]. Firstly, transformational leadership might be abused in a way it shapes followers' values or moves them towards new vision. Secondly, charismatic leaders may become dysfunctional or toxic to the organisation when an over-idealized leader instead of empowering their followers makes them helpless and results in failure leading to passivity. Thirdly, it can be seen as antidemocratic in creating vision independently of followers. Lastly, ${ }^{3}$ this model treats leadership as a personality feature rather than a skill that people can learn.

The first two criticisms relate to followers' well-being, their emotional and psychological state as well as health, and therefore should be considered in all kinds of activities - whether it is business or art organization - because there are examples of abuse (that should not be happening) in all of them. The third criticism seems more important to the business world, where engagement of employees in management and decision-making processes is a desired action, often leading to more engagement and better results. However, the aspect of democracy can be seen differently in the art world: it is common that directors follow their own ideas and do not engage in democratic processes; by doing so they actually achieve better artistic outcomes and create a characteristic style that can be used by others. Barba's dramaturgy may serve as an example of such an approach, which has gained a level where it is a new way of understanding dramaturgy established beyond any idiosyncratic ways. The last criticism seems the most important in case of change in leadership. The questions come to mind: will it be possible to find a good replacement for a transformational leader? Is it at all relevant to continue this model of leadership? Can this model of leadership stand a chance for success in managing the organization after generational change, with younger employees in the team ${ }^{24}$

\section{Transition process}

The plan for generational change in Odin Teatret was known to the public since 2014 [Bak 2014: 7]. The original scheme aimed at Barba's stepping down as Nordisk Teaterlaboratorium's director in 2018 with Julia Varley, a member of the ensemble and theatre's artistic coordinator, taking over his role. This was supposed to be followed

3 The literature mentions more criticism, but those examples that we chose are the most relevant to our case.

4 An interesting discussion of pros and cons of transformational leadership used in managing Millennials or GenMe generation can be found in work of Anderson et al. [2016]. 
by strengthening the Artists-in-Residence program and the future of Odin Teatret developed by visiting theatre groups according to their artistic vision. However, Barba's resignation was postponed until 2021 in order to ensure smooth generational change since the process required more time than previously expected [Adrian 2019: 8]. Nordisk Teaterlaboratorium started searching for Barba's replacement in March 2019. The new director should start on 1 January 2021, but already from autumn 2019 (s)he would be engaged in negotiations with Holstebro Municipality about a new regional theatre agreement for the 2021-2024 period [Nordisk Teaterlaboratorium - Odin Teatret 2019].

While the call for the new director did not specify formal requirements (like the candidate's education or experience), it described in detail the expectations towards the future director, with one being a priority: bringing "a suitable balance between tradition and change" [Nordisk Teaterlaboratorium - Odin Teatret 2019]. On the one hand, Odin Teatret was looking for someone who would continue tradition of the theatre and closely cooperate with the existing staff (Varley being mentioned in a call as remaining artistic coordinator). On the other hand, the new director should come with his own vision for the future and ability to implement it. This, of course, was not an easy task.

The tradition of the theatre laboratory combines a large range of activities (it is more than performing arts, including commitment to theatre education, outreach and theatre experiments). The organizational culture is described as interdisciplinary and diverse. It is visible in the call that the company would like to keep it that way, while change in leadership might affect it [Morcom 2012]. The attitude of the staff is portrayed not only as committed, but includes an emotional aspect: the "love for the organisation [that] has developed throughout many years" [Nordisk Teaterlaboratorium - Odin Teatret 2019]. This suggests that Nordisk Teaterlaboratorium is not only a place of work, but an organization very dear to many people, who invested large portions of their lives, identifying with it and presenting very emotional attitudes towards it and its future.

Additionally, it is important to remember that a new director would replace a famous theatre personality, Barba, who is theatre's founder, leader, visionary and outward face. This in itself are big shoes to fill. However, as mentioned above, this replacement concerns only Nordisk Teaterlaboratorium. Barba is not leaving the organization - he stays as Odin Teatret's artistic director. This means that a new director will first be working with Barba during the negotiating period, preparing the change that he will be implementing from 2021, but after that he will continue to have Barba in the organization - in the ensemble. This may cause two opposite effects: either aiding the change, especially keeping with the theatre's tradition; or slowing down the process of implementing the new vision. Nordisk Teaterlaboratorium seem to be aware of this problem and stresses in the call the need for managerial skills, strong vision (both artistic and organizational) and competence to implement it. 


\section{Discussion}

As we mentioned above, Nordisk Teaterlaboratorium - Odin Teatret is very much focused on preserving Barba's and theatre's legacy. Odin Teatret Archive (OTA), which started in 2008, is a project which seems to be gaining momentum. It is focused on archiving different material connected to activities of Odin Teatret: (1) archival memory (which is static and focused on papers, photographs and audiovisual material); (2) private memory (which manages oral sources: statements of the group theatre history's protagonists and some members of the audience); (3) social memory (description of different directions and of the collective research done within the theatre, e.g. monographic chapters); (4) historical memory (contextualization of the documents, searching for references in cultural history, politics and sociology); (5) technical-artistic memory (Barba's and other Odin Teatret actors' research on actor's craft valuable for theatre culture) [OTA]. Many of the sources are preserved in collaboration with the Royal Library in Copenhagen and through them made available to the public. One of the most interesting initiatives within this project is The Living Archives that focuses on "the creation of videos based on old documents as well as new materials prepared for the occasion" [The Living Archives]. Those initiatives are serving two purposes: archival and educational. Their second purpose is aimed both at teachers in theatre's history or method and at practitioners for the self-education.

This shows that Odin Teatret (with its ensemble) is very much interested in keeping their legacy alive. However, they do it mostly through archiving material for different purposes. What interests us, however, is the hypothetical possibility to continue the ensemble's work under a new direction and to provide live experience to the future audiences.

Returning to the questions we asked in the beginning of this article: (1) How would it have been possible to continue after such an influential director retired? (2) Would the next step be continuation or something new?

The reader might have noticed the usage of the word "how" in our first question. It is not a matter of whether or not replacement is possible, since we already know the replacement of Barba as artistic leader will never happen. We put forward this question merely as a hypothetical question: if it would have happened, how could one have conceived of the replacement of Barba as the artistic leader of group theatre Odin Teatret? Obviously, the answer to this question needs to be a complex one, as there are many factors supporting Barba in his artistic leadership as well as his personal wishes, deciding what would happen. Imagine that Barba had had the wish to pass on his method/dramaturgy in practice many years ago, this could have been done by Barba having an apprentice. This is not entirely unimaginable, since Barba himself had learned how to become a director, while being the apprentice of Grotowski. Had Barba been convinced that his method could be passed on, 
such an apprenticeship would have been conceivable. Taking into consideration Barba's intuitive, serendipic method in search of the organizational dramaturgical whole of the performance and the time needed for each performance to evolve, the apprenticeship would have had to be a long-term relationship between the master and the apprentice, where learning from observation and learning by doing would have been important and perhaps comparable to methods of Zen Buddhist masters. This relationship would have put many of the same requirements on the apprentice as the actors. Here Bass and Avolio's 4Is are applicable.

For our second question, the answer is seemingly more obvious: even when following Barba's method, the performances his follower would make, could never be the same; that would be like expecting a river to be the same one, the second time one steps into it. Of course, the circumstances would be different: the artistic director is no longer the same, the original actors might have been replaced, the ideas and the material the group theatre are working on are different. Only the method and the dramaturgy would remain. This would be the legacy and tradition passed on to the new generation, and used for producing new performances.

Nevertheless, besides this new line of performances by the new Odin Teatret, one could also imagine that a significant part of the old/current portfolio to be kept for posterity: through reenactment. This would involve the preservation of the detailed performance scores of the old performances, notes of director and actors, and other significant archival material in order for them to be restaged and reperformed by the new ensemble. In this way the results of Barba's original work could be kept alive and living. However, as reenactment this path would be placed between continuation and something new.

\section{Conclusion}

Change of the director of Nordisk Teaterlaboratorium - Odin Teatret and generational change in the organization is an immense challenge. The new post was given to Per Kap Bech Jensen, who has experience in managing and overseeing theatrical and cultural projects in Denmark and who has been working with the Odin Teatret as producer between 2005 and 2012, and with Nordisk Teaterlaboratorium as administrative director since 2014 [LinkedIn]. This long-term experience with the laboratory, working with Barba and members of the staff gives him indisputable insight into organizations' traditions and facile entry into managerial tasks. The future will show whether he is going to follow Barba's managerial style or develop the organization in a different way.

The future of Odin Teatret ensemble seems to be forgone: it is going to cease to exist, leaving The Living Archive behind as its memory. Barba's method and dramaturgy will continue to be practiced and developed: via researchers' work and Barba's followers. 
In this article, however, we hypothesized how the ensemble could continue, even without Barba. As we see it, a new director could either focus on continuing working with the method of Odin Teatret or on preserving the results of the method developed by Barba via reenactments of existing performances. We think that neither of the paths could simply keep the work of Barba unchanged. The new director (and new members of the theatre ensemble), even if they decide to reenact the performances and closely follow the scores, could not deliver the same enactments. The outcome would definitely undergo changes. The question remains: which approach - preserving the method (as a working process) or outcome of the method (via reenactments) - could keep the tradition of the theatre alive? Only the future can bring us answer: if not through Odin Teatret development, then through other examples of group theatres working with similar methods and under long-term leadership.

\section{Biblioģraphy}

About Odin Teatret, website, https://odinteatret.dk/about-us/about-odin-teatret/ [accessed: 20.04.2020].

Adrian R. (2019), Evaluering af egnsteatre i Danmark. Odin Teatret, https://odinteatret.dk/ media/5127/evaluering-odin-teatret-final2.pdf [accessed: 19.04.2020].

Anderson H., Baur J., Griffith J., Buckley M. (2016), What Works for You May Not Work for (Gen) Me: Limitations of Present Leadership Theories for the New Generation, "The Leadership Quarterly", Vol. 28, Iss. 1, p. 245-260. DOI: 10.1016/j.leaqua.2016.08.001.

Bak L. (2014), Evaluering af egnsteatre i Danmark. Odin Teatret, https://odinteatret.dk/media/2789/2014-06-evaluering-ot-ved-lene-bak.pdf [accessed: 19.04.2020].

Barba E. (2010), On Directing and Dramaturgy, London-New York: Routledge.

Bass B.M. (1999), Two Decades of Research and Development in Transformational Leadership, "European Journal of Work and Organizational Psychology", Vol. 8 (1), p. 9-32. DOI: 10.1080/135943299398410.

Bass B.M., Avolio B.J. (1994), Improving Organizational Effectiveness through Transformational Leadership, Thousand Oaks, CA: Sage Publications.

Boerner S., Streit Ch. von (2005), Transformational Leadership and Group Climate: Empirical Results from Symphony Orchestras, "Journal of Leadership and Organizational Studies", Vol. 12, p. 31-41.

Boerner S., Streit Ch. von (2007), Promoting Orchestral Performance: The Interplay between Musicians' Mood and a Conductor's Leadership Style, "Psychology of Music", Vol. 13, Iss. 1, p. 135-146. DOI: 13.10.1177/0305735607068891.

Bolden R. (2011), Distributed Leadership in Organizations: A Review of Theory and Research, "International Journal of Management Reviews", Vol. 13, p. 251-269. 
Bolden R., Hawkins B., Gosling J., Taylor S. (2011), Exploring Leadership: Individual, Organizational, and Societal Perspectives, Oxford: Oxford University Press.

Bratton J. (ed.) (2020), Organizational Leadership, London: Sage Publications Ltd.

Burns J.M. (1978), Leadership, New York: Harper \& Row.

Kark R., Shamir B., Chen G. (2003), The Two Faces of Transformational Leadership: Empowerment and Dependency, "Journal of Applied Psychology", Vol. 88, No. 2, p. 246-255.

LinkedIn, Per Kap Bech Jensen, website, https://www.linkedin.com/in/dramatisk/?originalSubdomain=dk [accessed: 20.04.2020].

The Living Archives, website, http://www.odinteatretarchives.com/thearchives/the-living-archives [accessed: 20.04.2020].

Morcom A. (2012), Transition of Artistic Leadership in a Theatre Company, "The International Journal of Knowledge, Culture, and Change Management: Annual Review”, Vol. 11, p. 237-246. DOI: 10.18848/1447-9524/CGP/v11i06/50216.

Nordisk Teaterlaboratorium - Odin Teatret, new director's job offer, 2019, website, https:// odinteatret.dk/news/nordisk-teaterlaboratorium-odin-teatret-seeks-a-new-director/\#Enclosure3 [accessed: 19.04.2020].

Northouse P.G. (2012), Leadership: Theory and Practice, London: SAGE Publications, Inc.

OTA, website, https://odinteatret.dk/research/ota/ [accessed: 20.04.2020].

Paavolainen T. (2015), Meaning in the Weaving: Mapping and Texture as Figures of Spatiality and Eventness, "Nordic Theatre Studies", Vol. 27 (2), p. 10-21.

Rowold J., Rohmann A. (2009), Transformational and Transactional Leadership Styles, Followers' Positive and Negative Emotions, and Performance in German Nonprofit Orchestras, "Nonprofit Management and Leadership", Vol. 20, p. 41-59. DOI: 10.1002/nml.240.

Turner C., Behrndt S.K. (2008), Dramaturgy and Performance, Basingstoke: Palgrave Macmillan. 